\title{
Promotion of flowering in Eucalyptus nitens by paclobutrazol was enhanced by nitrogen fertilizer
}

\author{
Dean R. Williams, Brad M. Potts, and Philip J. Smethurst
}

\begin{abstract}
We examined the effects of nitrogen and phosphorus fertilizer and paclobutrazol on flowering precocity and abundance in Eucalyptus nitens Deane \& Maid. Trials to test these effects consisted of a factorial nitrogen by phosphorus experiment replicated on two sites and factorial nitrogen by paclobutrazol experiments conducted separately on reproductively immature and reproductively mature trees. The increase in tree size due to nitrogen fertilization increased the occurrence and abundance of precocious flower buds. However, the increase in tree size alone could not account for the nitrogen effect on flowering, indicating a secondary mechanism of flower induction by nitrogen. The application of both nitrogen fertilizer and paclobutrazol substantially increased the occurrence of precociously flowering trees over that of either treatment applied alone. The efficacy of both paclobutrazol and nitrogen in stimulating the flowering of the reproductively mature trees was affected by soil type, but this effect was overcome through the combination of nitrogen and paclobutrazol. The combination of nitrogen and paclobutrazol also restricted tree growth and combined applications on nitrogen deficient sites will be beneficial in commercial systems for producing eucalypt seed.
\end{abstract}

Résumé : Nous avons étudié les effets d'un fertilisant contenant de l'azote et du phosphore et du paclobutrazol sur l'abondance et la précocité de la floraison chez Eucalyptus nitens Deane \& Maiden. Ces effets ont été testés à l'aide d'un dispositif factoriel avec l'azote et le phosphore répété dans deux sites et d'autres essais factoriels avec l'azote et le paclobutrazol établis séparément sur des arbres immatures incapables de se reproduire et sur des arbres matures capables de se reproduire. La dimension accrue des arbres due à la fertilisation azotée a augmenté la fréquence et l'abondance des bourgeons floraux précoces. Cependant, l'augmentation de la dimension des arbres ne peut à elle seule expliquer l'effet de l'azote sur la floraison, laissant supposer l'existence d'un mécanisme secondaire d'induction de la floraison par l'azote. L'application combinée d'un fertilisant azotée et du paclobutrazol a nettement augmenté la fréquence des arbres à floraison précoce comparativement à l'un ou l'autre des traitements appliqués seuls. L'efficacité du paclobutrazol et de l'azote à stimuler la floraison des arbres matures capables de se reproduire était influencée par le type de sol mais cet effet était surmonté par la combinaison de l'azote et du paclobutrazol. La combinaison de l'azote et du paclobutrazol limitait également la croissance des arbres et des applications combinées dans des sites déficients en azote seront bénéfiques dans les systèmes commerciaux de production de graines d'eucalyptus.

[Traduit par la Rédaction]

\section{Introduction}

With the rapid expansion of eucalypt plantations in temperate Australia (Anonymous 2000), a high demand has been placed on seed supplies, particularly for elite seed developed from breeding programs. An inherent problem with the supply of seed is that temperate eucalypts can be reproductively immature for up to 10 years (Moncur 1994). Once reproductive maturity has been reached seed production from some species can be poor and irregular (Moncur 1998). This is certainly the case for Eucalyptus nitens Deane \& Maid. (Jones et al. 2000), which is the major temperate

Received 28 December 2001. Accepted 8 August 2002.

Published on the NRC Research Press Web site at

http://cjfr.nrc.ca on 19 December 2002.

D.R. Williams ${ }^{1}$ and B.M. Potts. Cooperative Research Centre for Sustainable Production Forestry and School of Plant Science, University of Tasmania, G.P.O. Box 252-55, Hobart, Tasmania 7001, Australia.

P.J. Smethurst. Cooperative Research Centre for Sustainable Production Forestry and CSIRO Forestry and Forest Products, G.P.O. Box 252-12, Hobart, Tasmania 7001, Australia.

${ }^{1}$ Corresponding author (e-mail: Dean.Williams@utas.edu.au). eucalypt species planted in frost prone regions around the world (Tibbits et al. 1997).

A tool to maximize seed production in eucalypts is the plant growth regulator paclobutrazol ((2RS,3RS)-1-(4chlorophenyl)-4,4-dimethyl-2-1,2,4-triazol-1-yl-pentan-3-ol or PP333), which promotes precocious and abundant flowering. In adult $E$. nitens trees, application of paclobutrazol by soil drenching of the root zone vastly increases the abundance and reliability of the flower bud crop and subsequent seed harvest (Griffin et al. 1993). The actual dose of soil-applied paclobutrazol received by the tree is dependent on the physical and chemical properties of the soil including levels of organic matter, clay content, and cation exchange capacity, which can contribute to under- or over-dosing (Leaver 1986). In eucalypts, high dose rates of paclobutrazol result in reduced leaf size (Hetherington and Jones 1990) and number (Moncur and Hasan 1994). The resulting net reduction in photosynthetic capacity coupled with the high demand for assimilates by the increased number of flower buds tends to reduce seeds per capsule (Griffin et al. 1993) and the ability to maintain a high rate of flower bud initiation in subsequent seasons (Moncur et al. 1994b).

Only a small proportion of $E$. nitens seedlings have precociously flowered when treated with paclobutrazol (Moncur 
1998) and use of alternate growth regulators (chlormequat chloride and prohexadione) did not produce a significant flowering response (Williams et al. 1999). Precocious flowering in plants has been achieved by a number of nonhormonal cultural treatments, including girdling, root pruning, extended photoperiod, water stress, and fertilization (Chalupka and Cecich 1997). However, it is still not clear what mechanisms mediate this response (Bonnet-Masimbert and Webber 1995). One theory proposes that plants must reach a minimum size before reproductive growth can be initiated (Bernier et al. 1981). Treatments to accelerate early growth, such as extended photoperiod and fertilization, would reduce the time taken for plants to reach this minimum size and consequently first flowering (Hackett 1985).

Flower abundance in reproductively mature trees can be enhanced by fertilizer, especially nitrogen (Sedgley and Griffin 1989). Griffin et al. (1984) showed that nitrogen fertilizer improved flowering and seed yields substantially in mature Pinus radiata, but it was unclear if this effect was due to a direct florigenic effect of nitrogen or simply related to canopy growth. Enhanced canopy development is a drawback when using fertilizers in eucalypt seed orchards as it may impede access to flowers and capsules and increase canopy management costs (Eldridge et al. 1993).

The combined application of nitrogen fertilizer and paclobutrazol can benefit flowering whilst maintaining desirable canopy form when compared with applying them separately in peach (George and Nissen 1992) and pear (Raese and Burts 1983). A synergistic response may be produced by combinations of hormonal and cultural treatments exerting influence at different points in the flowering mechanism (Bonnet-Masimbert and Webber 1995). Cultural treatments can increase growth rates and the number of axillary meristems that potentially produce flowers whilst hormonal treatments can increase the proportion of these axillary meristems that develop into flowers (Bonnet-Masimbert and Webber 1995). Economically, the application of fertilizer, which is relatively cheap, may enhance the effectiveness of (the relatively expensive) paclobutrazol, reducing eucalypt seed production costs. This study investigates the effect of fertilizer application on its own and in combination with paclobutrazol on the initiation of flowering in both juvenile and mature trees of $E$. nitens.

\section{Materials and methods}

\section{The effect of fertilizer on flowering}

Two E. nitens fertilizer trials that had been established in spring 1993 were examined for the effects of nitrogen and phosphorus fertilization on flower bud production. These trials were located at Tim Shea in south-central Tasmania $\left(42^{\circ} 40^{\prime} \mathrm{S}, 146^{\circ} 28^{\prime} \mathrm{E}\right)$ and at Nunamara in the northeastern Tasmania $\left(41^{\circ} 23^{\prime} \mathrm{S}, 147^{\circ} 16^{\prime} \mathrm{E}\right)$; further details are given in Wang et al. (1998). Seedlings (6 months old) raised from open-pollinated orchard seed were planted $2.0 \mathrm{~m}$ apart within rows and $4.0 \mathrm{~m}$ between rows (1250 stems/ha). Two months after planting, the seedlings were given a spot dose of a 10:17:8 (N:P:K) fertilizer at a rate of $200 \mathrm{~g} / \mathrm{plant}$ at Nunamara and $100 \mathrm{~g} / \mathrm{plant}$ at Tim Shea. Intensive chemical weed control was employed in the first 18 months with additional mechanical slashing prior to each fertilizer applica-
Table 1. Dose rates and the timing (after planting) of nitrogen (applied as urea) and phosphorus (applied as triple super phosphate) fertilization of E. nitens trees growing at Tim Shea and Nunamara.

\begin{tabular}{llrrrr}
\hline \multirow{5}{*}{ Fertilizer } & & \multicolumn{4}{c}{ Rate $\left(\mathrm{kg} \cdot \mathrm{ha}^{-1}\right)$ of fertilizer application } \\
\cline { 3 - 6 } Nitrogen & Dose & & & & \\
& code & Year 1 & Year 2 & Year 3 & Total \\
\hline \multirow{5}{*}{ Phosphorus } & N1 & 0 & 0 & 0 & 0 \\
& N2 & 25 & 50 & 125 & 200 \\
& N3 & 50 & 100 & 150 & 300 \\
& N4 & 100 & 200 & 200 & 500 \\
& P2 & 0 & 0 & 0 & 0 \\
& P3 & 150 & 0 & 0 & 75 \\
\end{tabular}

Note: The experiment consisted of a $4 \times 3$ factorial of nitrogen (N1-N4) and phosphorus (P1-P3) with 25 trees per treatment replicated 3 times at each site.

tion. The fertilizer treatments were a factorial of four levels of nitrogen $(\mathrm{N} 1-\mathrm{N} 4)$ as urea $(46 \% \mathrm{~N})$ and three levels of phosphorus (P1-P3) as triple superphosphate $(20 \% \mathrm{P})$. The fertilizers were hand broadcast over three consecutive years (Table 1). Experimental plots were 5 rows by 5 trees $(25$ trees per plot) with two untreated tree buffers separating each plot. The trials composed of three replicates with all treatments randomized within each replicate.

Stem height and diameter at breast height (DBH; $1.3 \mathrm{~m})$ were measured at ages 2.5 and 3.5 years and DBH only at age 4.5 years. Individual tree height at 4.5 years was estimated from site-specific linear regressions with $\mathrm{DBH}$ derived from the measurements of five diameter classes per plot (R. Cromer, personal communication). Survival in all plots was high. Eucalyptus nitens requires a full, cold winter to initiate flowering (Moncur and Hasan 1994), and the flower buds begin to develop in late winter - early spring and are most conspicuous 12-16 months later (Moncur et al. 1994a). When trees were 3.5 and 4.5 years old (approximately 12 months after the initiation period) a visual estimation of the number of flower bud umbels was made by counting the number of umbels in a cluster and multiplying that by the number of equivalent clusters visually grouped around the canopy.

A linear model was fitted to the plot means for height and $\mathrm{DBH}$, and proportion (range 0-1) of trees with umbels. Analyses were undertaken on the combined data for both sites using the model:

$$
\begin{aligned}
\text { Trait }=\text { mean }+\operatorname{cov}+\operatorname{cov} \times \text { site }+ \text { site } \\
+\operatorname{rep}(\text { site })+\mathrm{N}+\mathrm{P}+\mathrm{N} \times \mathrm{P}+\mathrm{N} \times \text { site } \\
+\mathrm{P} \times \text { site }+\mathrm{N} \times \mathrm{P} \times \text { site }+ \text { error }
\end{aligned}
$$

where cov is the relevant covariate (height or $\mathrm{DBH}$ ), site is the fixed location (Tim Shea or Nunamara) effect, rep(site) is the random effect of replicate (1-3) within site, $\mathrm{N}$ is the fixed effect of nitrogen $(\mathrm{N} 1-\mathrm{N} 4), \mathrm{P}$ is the fixed effect of phosphorus (P1-P3), and the remaining terms are the fixed two- and three-way interactions. The rep(site) effect was used to obtain an approximate test of the significance of the site effect, whereas the significance of all other terms was tested against the error. The analysis of the effect of the treatment on the number of umbels per tree used individual 
tree data. This analysis was restricted to only those trees with umbels because of the low frequency of reproductive trees ( $n=80$ and 522 at 3.5 and 4.5 years old, respectively). The model fitted was the same as eq. 1 except that an additional random term $\mathrm{N} \times \mathrm{P} \times \operatorname{rep}($ site) was included, and it was this term that was used to test the significance of the treatment effects.

The data for each trait was initially fitted to eq. 1 without the $\operatorname{cov}$ and $\operatorname{cov} \times$ site terms to test for the treatment effects on overall flowering. When a treatment effect was found to be significant, the cov and $\operatorname{cov} \times$ site terms were included in the model (eq. 1), and the data was re-analysed to find whether the observed responses could be attributed to either height, DBH, or their interactions with trial site or was a direct florigenic effect. The tree size traits (height and DBH) from the year prior to the umbel assessment were used as the covariate in the analysis for the proportion of trees with umbels, as a surrogate for tree size during umbel induction. Tree size traits from the same year as the umbel assessment were used as covariates in the analysis of the number of umbels per tree as a surrogate for the number of axillary site available from which umbels could develop.

The site and associated interaction terms were removed from eq. 1 for individual site analysis when there was a significant site by treatment interaction. Specific contrasts among the treatments of each main effect ( $\mathrm{N}$ and $\mathrm{P}$ ) alone and in combination were undertaken, and their least square means were calculated for each trait based on plot means except the number of umbels per tree, which was based on only those trees with umbels. Angular and $\log _{10}$ transformations of the raw data were undertaken for the proportion of trees with umbels and number of umbels per reproductive tree, respectively, to normalize the residuals and homogeneity of the error variances, and results were back transformed for presentation. The models were fitted using the PROC MIXED procedure in SAS (SAS Institute Inc. 1992). Pearson correlations between tree size and either the number of umbels per reproductive tree or the proportion of trees with umbels were calculated based on single tree data using PROC CORR in SAS (SAS Institute Inc. 1992).

\section{Response of reproductively immature trees to paclobutrazol combined with nitrogen fertilizer}

The trial site was located near Hampshire in northwestern Tasmania $\left(41^{\circ} 18^{\prime} \mathrm{S}, 145^{\circ} 42^{\prime} \mathrm{E}\right)$ and $4 \mathrm{~km}$ west of the Basils-2 site described in Wang et al. (1998). Ramets from rooted cuttings of two proprietary genotypes of E. nitens (clones 1 and 2) were planted in adjacent clonal blocks 6 months after striking at a spacing of $2.6 \mathrm{~m}$ within rows and $3.5 \mathrm{~m}$ between rows (1100 stems/ha). All plants received $100 \mathrm{~g}$ of a 18:20:0 (N:P:K) diamonium phosphate fertilizer soon after planting. At age 2.5 years (November 1996), $2 \times 2$ tree treatment plots were established with a minimum of 2 untreated buffers trees separating plots. Trees in each plot were measured for height and stem diameter at $15 \mathrm{~cm}$ from ground level and the presence or absence of flower buds noted prior to treatment. Treatments were a $3 \times 3$ factorial combination of three levels of nitrogen; 0 (control), 50 , and $150 \mathrm{~kg} \cdot \mathrm{ha}^{-1}$ total $\mathrm{N}$ (equivalent to $0,45.5$ and $136.4 \mathrm{~g}$ total $\mathrm{N} /$ tree respectively), and three levels of paclobutrazol; 0 (control), 0.3, and $1.0 \mathrm{~g} \cdot \mathrm{cm}^{-1}$ of stem circumference $\left(\mathrm{g} \cdot \mathrm{cm}^{-1} \mathrm{circ}\right)$ mea- sured at $15 \mathrm{~cm}$ height (Griffin et al. 1993). The per-tree dose of nitrogen was applied as urea in a single spade slit ca. $20 \mathrm{~cm}$ from the base of the tree in November 1996. The paclobutrazol as Cultar ${ }^{\circledR}\left(250 \mathrm{~g} \cdot \mathrm{L}^{-1}\right.$ paclobutrazol, ICI) was dispersed in $1 \mathrm{~L}$ of water and applied as a collar drench in February 1997. Treatments were replicated seven and eight times for clones 1 and 2, respectively, and the treatment plots were completely randomized within replicates. Mortality in the trial was very low and final measurements for height and stem diameter (at $15 \mathrm{~cm}$ above the ground) and a count of the number of umbels per tree were made when trees were 4.0 years old.

A linear model was fitted to the plot means for the traits of height, diameter, and proportion (range 0-1) of trees with flower buds. The analysis was done on the combined data for both clones using the model:

$$
\begin{aligned}
\text { Trait }= & \text { mean }+\operatorname{cov}+\operatorname{cov} \times \mathrm{cl}+\mathrm{cl} \\
+ & \operatorname{rep}(\mathrm{cl})+\mathrm{N}+\mathrm{pac}+\mathrm{N} \times \mathrm{pac}+\mathrm{N} \\
& \times \mathrm{cl}+\mathrm{pac} \times \mathrm{cl}+\mathrm{N} \times \mathrm{pac} \times \mathrm{cl}+\text { error }
\end{aligned}
$$

where cov is the relevant covariate (height or stem diameter), $\mathrm{cl}$ is the fixed clone (clone 1 or clone 2) effect, rep(cl) is the random effect of replicate (1-7 or 8) within clone, $\mathrm{N}$ is the fixed effect of nitrogen $\left(0,50,150 \mathrm{~kg} \cdot \mathrm{ha}^{-1}\right)$, pac is the fixed effect of paclobutrazol $\left(0,0.3,1.0 \mathrm{~g} \cdot \mathrm{cm}^{-1} \mathrm{circ}\right)$, and the remaining terms are the fixed two- and three-way interactions. The rep $(\mathrm{cl})$ effect was used to obtain an approximate test of the significance of the clone effect, whereas the significance of all other terms was tested against the error. The analysis of the effect of the treatment on the number of umbels per tree used individual tree data. This analysis was restricted to only those trees with umbels and treated with both nitrogen and paclobutrazol because of the low frequency of trees bearing umbels $(n=89)$. The model fitted was the same as eq. 2 except that an additional random term $\mathrm{N} \times$ pac $\times \operatorname{rep}(\mathrm{cl})$ was included, and it was this term that was used to test the significance of the treatment effects.

The data for each trait was initially fitted to eq. 2 without the cov and $\operatorname{cov} \times \mathrm{cl}$ terms to test for the treatment effects on overall flowering and growth. As previously noted, when a treatment effect was found to be significant, these covariate terms were included in the model to find whether the observed responses could be attributed either to height, diameter, or their interactions with genotype. The mean initial height or diameter of the plot was used as a covariate for the proportion of trees with umbels, and final tree height or diameter was used as a covariate when analysing for the number of umbels per tree at age 4 years.

Angular and $\log _{10}$ transformations of the raw data were undertaken for the proportion of trees with umbels and number of umbels per reproductive tree, respectively, to normalize the residuals and homogeneity of the error variances and results were back transformed for presentation. The model was fitted to the data to produce specific contrasts, leastsquares means and standard errors for the main effects of nitrogen and paclobutrazol using the MIXED procedure of SAS (SAS Institute Inc. 1992). To test if there was a relationship between initial and final tree size and the presenceabsence and abundance of flowering, respectively, Pearson correlations between these traits were also calculated based 
Fig. 1. Least squares means of the effect of nitrogen $(\mathrm{N})$ and paclobutrazol on the proportion of 4.0-year-old trees with umbels and tree height, 1.5 years after treatment $(n=540)$. The dose rate of paclobutrazol $(0,0.3$, or 1.0$)$ is the number of grams applied per centimetre of stem circumference measured at a height of $15 \mathrm{~cm}$ and delivered as a collar drench, whilst the nitrogen was applied at the specified rates $\left(0,50\right.$, or $\left.150 \mathrm{~kg} \cdot \mathrm{ha}^{-1}\right)$ by spade slit. Error bars are SEs.

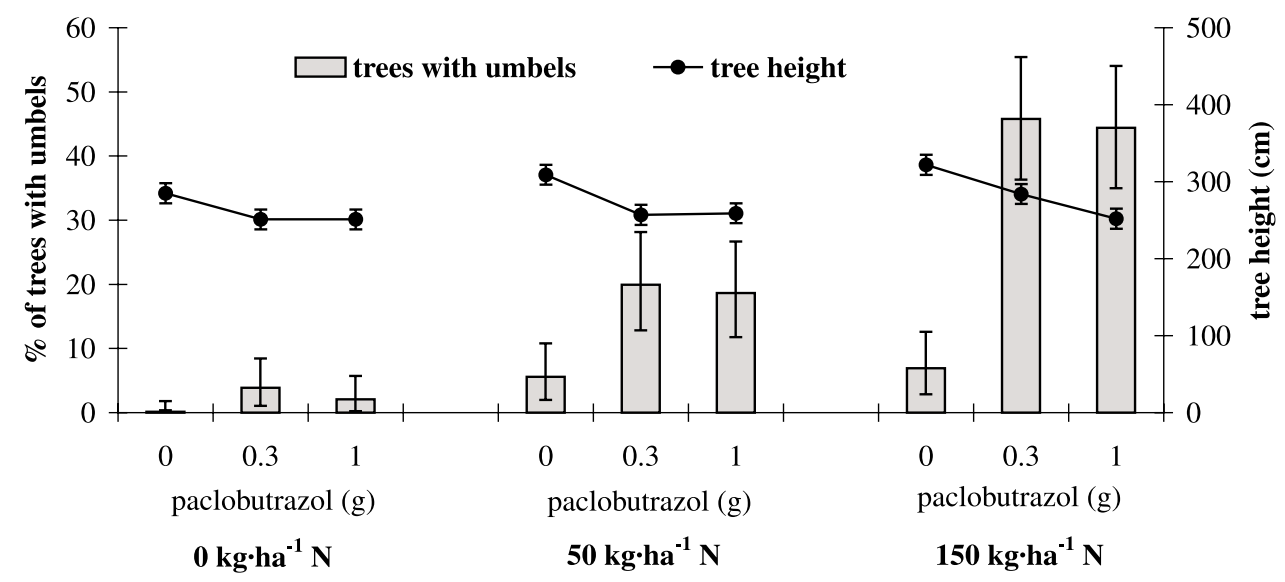

on single tree data using PROC CORR of SAS (SAS Institute Inc. 1992).

\section{Response of reproductively mature trees to paclobutrazol combined with nitrogen fertilizer}

The trial site was located adjacent to the Nunamara site described above and was part of the initial establishment but not utilized in that study. Treatments were a $2 \times 2$ factorial with two levels of nitrogen $\left(0\right.$ and $\left.300 \mathrm{~kg} \cdot \mathrm{ha}^{-1}\right)$ and two levels of paclobutrazol ( 0 and $1.0 \mathrm{~g} \cdot \mathrm{cm}^{-1}$ circ at breast height) (Griffin et al. 1993), which were applied when trees were 4 years old (February 1997). Each combination was applied to $2 \times 2$ tree plots with a minimum of 2 untreated tree buffers separating plots. Trees were measured for height and $\mathrm{DBH}$, and the presence of umbels was noted prior to treatment. The nitrogen was hand broadcast as urea across a $4 \times 8 \mathrm{~m}$ area in which the plot was centred and the paclobutrazol as Cultar $^{\circledR}\left(250 \mathrm{~g} \cdot \mathrm{L}^{-1}\right.$ paclobutrazol; ICI) was dispersed in $1 \mathrm{~L}$ of water and applied as a collar drench. Treatments were replicated seven times on each of two distinctly different coloured soils present at the site, one red (basalt parent rock) the other grey (dolerite parent rock) with treatments randomized within each replicate. The red soil type was taxanomically classed as a Eutrudox (Smethurst et al. 2002) with a $\mathrm{pH}$ of 5.7 and total $\mathrm{N}$ concentration of $0.27 \%$ (Wang et al. 1998), whilst the grey soil was similar to an Albaqualf, which typically has a $\mathrm{pH}$ of 5.9 and a total $\mathrm{N}$ concentration of $0.25 \%$ (Grant et al. 1995). When trees were 5.5 years old, height and DBH were measured, and the number of umbels per tree was estimated as previously described. The effect of nitrogen, paclobutrazol, and soil type on plot means for the traits of height, diameter, and the presence of flower buds was determined using eq. 2, where clone was replaced with soil type in the model. The analysis of these effects on the number of umbels per tree was carried out likewise, except it was performed on single tree data and only on those trees with umbels $(n=150)$. In this analysis, an additional random term $\mathrm{N} \times$ pac $\times \operatorname{rep}($ soil) was included and was used to test the significance of the treatment effects. The data was transformed, and specific contrasts, least-squares means, and standard errors for each trait and correlations between tree size and reproductive traits performed as described previously.

\section{Results}

\section{Reproductive response to fertilizer}

Nitrogen treatment had no significant $(p>0.05)$ overall effect on the proportion of trees with umbels at either ages 3.5 or 4.5 years in the fertilizer trials but, at age 4.5 years, significantly $(p<0.01)$ increased the number of umbels per reproductive tree. There was a significant difference $(p<0.05)$ between sites in the proportion of trees with umbels and a significant interaction between the effects of nitrogen and site on the number of umbels per reproductive tree $(p<0.05)$ at 4.5 years old. However, when tree size (height and DBH) was included as a covariate, it was the most significant factor affecting both the presence and abundance of umbels $(p<0.01)$ at both sites in the MIXED models. This was consistent with the significant $(p<0.001)$ positive Pearson's correlation coefficients observed between tree size and reproductive traits. When either mean height or DBH was included as a covariate, the individual effect of nitrogen on the number of umbels per tree was no longer significant $(p>0.05)$, but the nitrogen $\times$ site interaction remained significant $(p<0.05)$. In the analysis for each site with the covariate, this interaction was found to be due to nitrogen significantly increasing the number of umbels per reproductive tree at Tim Shea but not at Nunamara. At Tim Shea the mean number of umbels per reproductive tree increased from 52 in the control plots to 97 in the N4 treatment, whilst at Nunamara the respective treatment yielded only 35 and 39 umbels per reproductive tree. This differential response may be due to higher levels of naturally available nitrogen at Tim Shea compared with Nunamara (Wang et al. 1998). Phosphorus had no significant effect $(p>0.05)$ on tree size or reproductive development.

\section{Response of reproductively immature trees to paclobutrazol combined with nitrogen fertilizer}

The combination of the highest dose of nitrogen and either dose rate of paclobutrazol induced the greatest proportion of previously reproductively immature trees at the 
Fig. 2. Least squares means of the effect of nitrogen $(\mathrm{N})$ and paclobutrazol on the number of umbels per reproductive tree at 4.0 years old, 1.5 years after treatment $(n=89)$. The dose rate of paclobutrazol $(0.3$ or 1.0$)$ is the number of grams applied per centimetre of stem circumference measured at a height of $15 \mathrm{~cm}$ and delivered as a collar drench, whilst the nitrogen was applied at the specified rates $\left(50\right.$ or $\left.150 \mathrm{~kg} \cdot \mathrm{ha}^{-1}\right)$ by spade slit. Error bars are SEs.

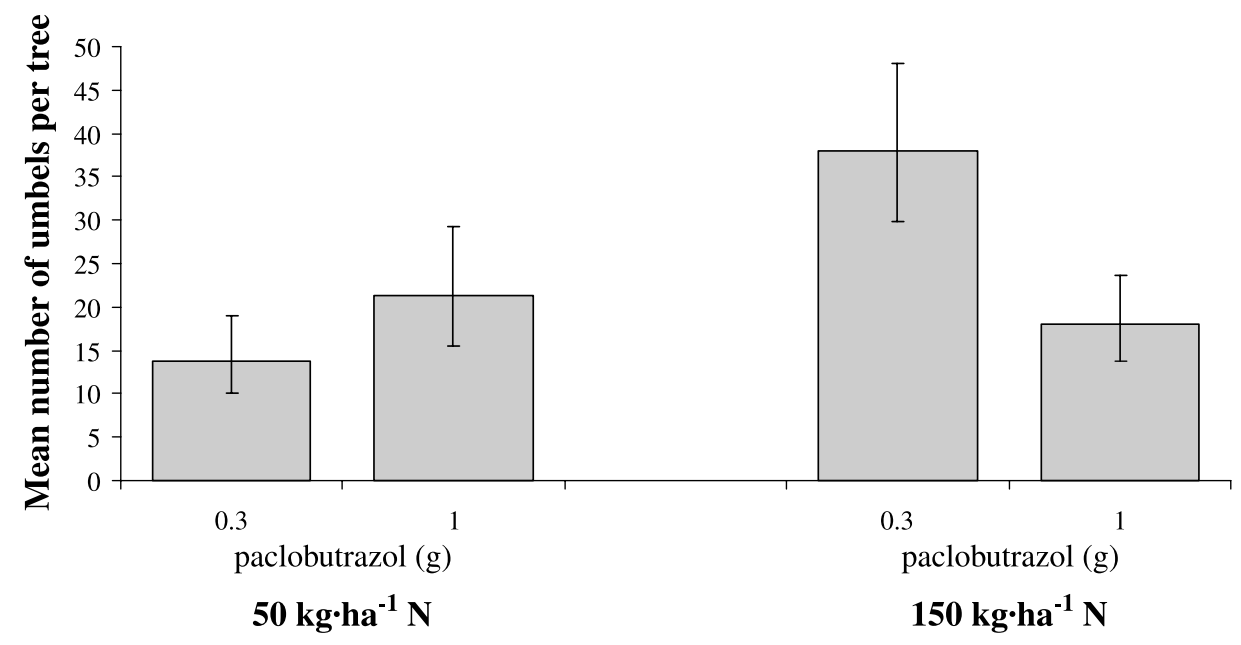

Hampshire site to develop umbels in the subsequent season (Fig. 1). There were significant effects of nitrogen $(p<0.001)$, paclobutrazol $(p<0.001)$, and clone $(p<0.05)$ on the proportion of trees with umbels. Whilst initial tree height and diameter also had significant positive effects $(p<0.001)$ on the proportion of trees with umbels ( $r=0.43$ and $r=0.39$, respectively) when these traits were included as a covariate in the model, they could not account for the main treatment effects, which remained significant $(p<0.001)$. The inclusion of either tree size trait as a covariate in the model removed the significance of the clone effect $(p>0.05)$, as initial and final mean height and initial and final mean diameter of clone 1 was $15.0,14.8,17.6$, and $13.5 \%$ greater than clone 2 , respectively.

There was no significant difference $(p>0.05)$ among treatments in initial tree height or diameter. However, tree height and diameter after treatment was significantly affected by both nitrogen ( $p<0.05$ and $p<0.001$, respectively) and paclobutrazol ( $p<0.001$ and $p<0.01$, respectively). Where nitrogen and paclobutrazol treatments were combined, mean tree height was not significantly different $(p>0.05)$ from trees treated with paclobutrazol only except where the high dose of nitrogen $\left(150 \mathrm{~kg} \cdot \mathrm{ha}^{-1}\right)$ and the low dose of paclobutrazol $\left(0.3 \mathrm{~g} \cdot \mathrm{cm}^{-1}\right)$ were applied together (Fig. 1).

Whilst there was little difference in the proportion of trees with umbels between the two levels of paclobutrazol at the higher nitrogen level (Fig. 1), more umbels occurred on trees treated with the high rate of nitrogen and the low rate of paclobutrazol (Fig. 2). For the subset of trees receiving both nitrogen and paclobutrazol, the interaction between nitrogen and paclobutrazol on the number of umbels per tree was significant $(p<0.05)$. However, this appeared to be mainly a result of the greater tree size of the $150 \mathrm{~kg} \cdot \mathrm{ha}^{-1}$ nitrogen and $0.3 \mathrm{~g} \cdot \mathrm{cm}^{-1}$ paclobutrazol treated trees (Fig. 1). The number of umbels per tree was positively correlated with both final tree height $(r=$ 0.23, $p<0.0001)$ and diameter $(r=0.21, p<0.0001)$.

\section{Response of reproductively mature trees to paclobutrazol combined with nitrogen fertilizer}

At Nunamara, nitrogen or paclobutrazol applied alone in- creased the number of reproductively mature trees with umbels to some degree 1.5 years after treatment (Fig. 3). However, only a combined treatment of nitrogen and paclobutrazol resulted in a high proportion of trees with umbels on both soil types (Fig. 3). When DBH when treated was included as a covariate there were clear two-way interactions between soil type and nitrogen as well as soil type and paclobutrazol $(p<0.05)$. Nitrogen had a significant effect $(p<0.05)$ only on the grey soil type. The effect of paclobutrazol was highly significant on the red soil type $(p<$ $0.001)$ but diminished on the grey soil $(p<0.05)$. It was only in the presence of nitrogen that paclobutrazol was able to stimulate a high proportion of trees to produce umbels on the grey soil type. However, the three-way interaction was not significant. Initial tree height and diameter had significant $(p<0.01)$ positive effects on the presence of new umbels ( $r=0.22$ and $r=0.19$, respectively).

The mean number of umbels per tree was not significantly affected $(p>0.05)$ by soil type nor its interaction with the treatments applied. It was only paclobutrazol that had a significant effect $(p<0.001)$ with its application resulting in a mean increase from 13 and 16 umbels per tree in the controls to 118 and 136 umbels per paclobutrazol-treated tree without and with nitrogen application, respectively, on both soil types. Final mean tree height was significantly reduced by paclobutrazol treatment $(p<0.001)$ but was not affected significantly $(p>0.05)$ by the application of nitrogen fertilizer necessary to consistently increase the proportion of trees with umbels. Consequently, final tree height was not significantly correlated $(p>0.05)$ with umbel abundance. The combined treatment of nitrogen and paclobutrazol, therefore, resulted in greater and more consistent reproductive output without stimulating excessive canopy growth.

\section{Discussion}

The effectiveness and reliability of paclobutrazol in promoting flowering in E. nitens can be improved through the application of nitrogen fertilizer. The combined effects of nitrogen and paclobutrazol in promoting precocious umbel ini- 
Fig. 3. Least squares means of the effect of nitrogen $(\mathrm{N})$ and paclobutrazol on the proportion of 5.5-year-old trees with umbels on two different soil types, assessed 1.5 years after treatment and with stem diameter when treated included as a covariate $(n=224)$. The dose rate of paclobutrazol ( 0 or 1.0) is the number of grams applied per centimetre of stem circumference measured at breast height and delivered as a collar drench, whilst the nitrogen was applied at the specified rates $\left(0\right.$ or $\left.300 \mathrm{~kg} \cdot \mathrm{ha}^{-1}\right)$ by hand broadcast. Error bars are SEs.



tiation on 2.5-year-old trees appeared to be more than additive, analogous to the hormonal and cultural treatment effects described by Bonnet-Masimbert and Webber (1995).

Precocious reproductive development was most commonly associated with greater mean tree size in all experiments. Increases in the mean of both height and $\mathrm{DBH}$ significantly increased the occurrence of first flowering (precocity) and the abundance of umbels in trees from 3.5 to 5.5 years old. A similar relationship between tree size and flowering precocity was found in 4.0-year-old E. regnans (Cameron and Kube 1983) and 4.0-year-old E. globulus (Chambers et al. 1997), supporting the suggestion that plant size or growth rate are significant factors in determining when first flowering will occur (Hackett 1985). These correlations are phenotypic, in most cases reflecting an environmental (treatment) correlation, and should not be confused with the absence of a significant genetic correlation between precocious flowering and early growth in E. globulus reported by Chambers et al. (1997).

Increased tree size also significantly increased the abundance of umbels on flowering trees at 4.5 and 5.5 years of age. This relationship had been reported in a number of young $(<10$ years old) orchard-grown forest tree species including Pinus contorta (Wheeler et al. 1982), P. halepensis (Matziris 1997), $P$. radiata (Griffin et al. 1984), and E. regnans (Cameron and Kube 1983). However, this relationship may occur only under certain growing conditions and may not persist as trees age. For example, Griffin (1980) found flowering intensity to be independent of tree size in a mature (trees $>15$ years old) natural stand of $E$. regnans.

Accelerating tree growth through the application of fertilizer, specifically nitrogen, can decrease the time to first flowering and increase flower abundance. This was shown in trees up to 5.5 years old and may have potential benefits in older trees as well. Nitrogen fertilizer was more effective than the more conventionally used paclobutrazol at stimulating flowering in the reproductively immature $E$. nitens trees at Hampshire (Fig. 1). The application of nitrogen fertilizers has been shown to significantly improve growth rates in E. globulus up to 9.5 years old and E. nitens to at least 7.0 years old (Neilsen 1996; Turnbull et al. 1997). Indeed,
Cameron and Kube (1983) believed their observed increase in flower abundance in E. regnans was merely a function of tree size. However, the present study indicated nitrogen can also significantly increase both the proportion of trees with umbels and the abundance of umbels per tree, independent of the effect of tree size. This is consistent with results in horticultural and forest tree species where fertilizing with nitrogen has been used as a flower or cone induction tool for many years (Jackson and Sweet 1972; Sedgley and Griffin 1989; Owens 1991).

Paclobutrazol is used widely in eucalypt orchards to increase flowering and seed production. However, environmental conditions can alter the effectiveness of paclobutrazol, particularly when applied as a soil treatment (Leaver et al. 1982; Moncur et al. 1994b; Swain and Chiappero 1998). This variable response was clearly seen in the experiment at Nunamara when paclobutrazol was applied across two soil types. Although it is not clear what properties of the soil altered the effectiveness of paclobutrazol, there was a substantial benefit in coapplication of nitrogen in all cases.

The ability to control growth is a further benefit of the combined nitrogen and paclobutrazol treatment. With the inherent difficulties of crown management when working with fast-growing forest tree species (Eldridge et al. 1993), the application of luxuriant levels of fertilizer could magnify the problem. However, regardless of nitrogen dose, in all treatments with paclobutrazol, the mean height of trees was less than that of the controls. By balancing the treatments, tree height can be restricted, and the seed crop produced, closer to the ground. This would appear to contradict the earlier findings that larger trees produce more umbels. In these cases, as noted by Wheeler et al. (1982) it is likely to be the number of potential flowering sites per tree, not tree size per se that determines flowering abundance.

The dose rate of paclobutrazol that provided the best levels of flower initiation and abundance and growth control was $0.3 \mathrm{~g} \cdot \mathrm{cm}^{-1}$ of stem circumference. This result is largely based on comparisons with the higher $1.0 \mathrm{~g} \cdot \mathrm{cm}^{-1}$ of stem circumference dose at the Hampshire site (Figs. 1 and 2) providing there was good nitrogen availability. As a guide to what level of nitrogen supply might be necessary for opti- 
mum flower production, the strong associations with tree size suggests that the methods available for determining the best rate of application for growth (Judd et al. 1996; Misra et al. 1998) would be suitable.

In conclusion, mean tree size has a major impact on flowering in E. nitens with phenotypically larger plots flowering earlier and more abundantly. Many of the reproductive responses to fertilizer are mediated through the effect on tree size rather than by direct means. However, nitrogen does affect flowering precocity and abundance in a way that could not be accounted for by mean tree size. The reliability of either nitrogen or paclobutrazol as a flowering promoter can vary with soil type. A more reliable response from paclobutrazol can be achieved through the combined application with nitrogen. In reproductively immature trees, flowering precocity was markedly enhanced by the combined application of paclobutrazol and nitrogen. In reproductively mature trees, the response to paclobutrazol was more uniform across soil types after nitrogen application.

\section{Acknowledgments}

This research was supported by a post-graduate research fellowship from the Cooperative Research Centre for Sustainable Production Forestry to D.R.W. We thank Gunns Ltd., Norske Skog, and CSIRO for access to the sites and establishing the nitrogen and phosphorus fertilizer experiment; Dr. Carolyn Raymond and Greg Dutkowski for reviewing the manuscript; and Prof. Jim Reid for discussion and advice.

\section{References}

Anonymous. 2000. Plantations for Australia on target for 2020 vision. South. Hemisphere For. Ind. J. 6: 8-10.

Bernier, G., Kinet, J.M., and Sachs, R.M. 1981. The physiology of flowering. Vol. 1. CRC Press, Boca Raton, Fla.

Bonnet-Masimbert, M., and Webber, J.E. 1995. From first flower induction to seed production in forest tree orchards. Tree Physiol. 15: 419-426.

Cameron, J.N., and Kube, P.D. 1983. Management of seedling seed orchards of Eucalyptus regnans - selection, strategy and flowering study. Silvicultura, 32: 765-768.

Chalupka, W., and Cecich, R.A. 1997. Control of the first flowering in forest trees. Scand. J. For. Res. 12: 102-111.

Chambers, P.G.S., Potts, B.M., and Tilyard, P.A. 1997. The genetic control of flowering precocity in Eucalyptus globulus ssp. globulus. Silvae Genet. 46: 207-214.

Eldridge, K.G., Davidson, J., Harwood, C.E., and van Wyk, G. 1993. Eucalypt domestication and breeding. Oxford Press, Oxford, U.K.

George, A.P., and Nissen, R.J. 1992. Effects of water stress, nitrogen and paclobutrazol on flowering, yield and fruit quality of the low-chill peach cultivar, 'Flordaprince'. Sci. Hortic. 49: 197-209.

Grant, J.C., Laffan, M.D., Hill, R.B., and Neilsen, W.A. 1995. Forest soils of Tasmania. Forestry Tasmania, Hobart, Tasmania.

Griffin, A.R. 1980. Floral phenology of a stand of mountain ash (Eucalyptus regnans F. Muell) in Gippsland, Victoria. Aust. J. Bot. 28: 393-404.

Griffin, A.R., Crane, W.J.B., and Cromer, R.N. 1984. Irrigation and fertiliser effects on productivity of a Pinus radiata seed orchard: response to treatment of an established orchard. N.Z. J. For. Sci. 14: $289-302$.

Griffin, A.R., Whiteman, P., Rudge, T., Burgess, I.P., and Moncur, M. 1993. Effect of paclobutrazol on flower-bud production and vegetative growth in two species of Eucalyptus. Can. J. For. Res. 23: $640-647$.

Hackett, W.P. 1985. Juvenility, maturation, and rejuvenation in woody plants. Hortic. Rev. 7: 109-155.

Hetherington, S., and Jones, K.M. 1990. Effectiveness of paclobutrazol in retarding growth of Eucalyptus globulus seedlings. Can. J. For. Res. 20: 1811-1813.

Jackson, D.I., and Sweet, G.B. 1972. Flower initiation in temperate woody plants. Hortic. Abstr. 42: 9-24.

Jones, W.R., Clarke, C.R.E., and van Staden, J. 2000. Understanding the breeding system of cold tolerant Eucalyptus species and its impact on seed production. In Proceedings of the IUFRO Working Party 2.08.01 Tropical Species Breeding and Genetic Resources: Forest Genetics for the Next Millennium, 8-13 Oct. 2000, Durban, South Africa. Institute for Commercial Forestry Research, Scottsville, South Africa. pp. 146-150.

Judd, T.S., Bennett, L.T., Weston, C.J., Attiwill, P.M., and Whiteman, P.H. 1996. The response of growth and foliar nutrients to fertilisers in young Eucalyptus globulus (Labill.) plantations in Gippsland, southeastern Australia. For. Ecol. Manage. 82: 87-101.

Leaver, B.G. 1986. 'Cultar' - a technical overview. Acta Hortic. 179: 459-466.

Leaver, B.G., Shearing, S.J., and Batch, J.J. 1982. PP 333 - a new broad spectrum growth retardant. In Proceedings 1982 British Crop Protection Conference - Weeds, 22-25 Nov. 1982, Brighton, U.K. Vol 1. BCPC Publications, Croydon, U.K. pp. 3-10.

Matziris, D. 1997. Variation in growth, flowering and cone production in a clonal seed orchard of aleppo pine grown in Greece. Silvae Genet. 46: 224-228.

Misra, R.K., Turnbull, C.R.A., Cromer, R.N., Gibbons, A.K., LaSala, A.V., and Ballard, L.M. 1998. Below- and above-ground growth of Eucalyptus nitens in a young plantation II. Nitrogen and phosphorus. For. Ecol. Manage. 106: 295-306.

Moncur, M.W. 1994. Flower induction and enhancement in tropical species. In Proceedings of the International Symposium on Genetic Conservation and Production of Tropical Forest Tree Seed, 14-16 June 1993, Chiang Mai, Thailand. Edited by R.M. Drysdale, S.E.T. John, and A.C. Yapa. ASEAN-Canada Forest Tree Seed Centre, Mual-Lek, Saraburi, Thailand. pp. 173-181.

Moncur, M.W. 1998. Hastening seed production: a tool for increasing the rate of genetic improvement in eucalypt species. In Tree improvement applied research and technology transfer. Edited by S. Puri. Science Publishers Inc., Enfield, N.H. pp. 81-93.

Moncur, M.W., and Hasan, O. 1994. Floral induction in Eucalyptus nitens. Tree Physiol. 14: 1303-1312.

Moncur, M.W., Hand, F.C., and Ramsden, N.G. 1994a. Environmental and cultural effects on flowering and seed production of plantation grown Eucalyptus nitens. CSIRO Division of Forestry, Hobart, Tasmania.

Moncur, M.W., Rasmussen, G.F., and Hasan, O. 1994b. Effect of paclobutrazol on flower-bud production in Eucalyptus nitens espalier seed orchards. Can. J. For. Res. 24: 46-49.

Neilsen, W.A. 1996. Response of Eucalyptus nitens and Eucalyptus regnans seedlings to application of various fertilisers at planting or soon after planting. N.Z. J. For. Sci. 26: 355-369.

Owens, J.N. 1991. Flowering and seed set. In Physiology of trees. Editied by A.S. Raghavendra. John Wiley \& Sons, Inc., New York. pp. 247-271. 
Raese, J.T., and Burts, E.C. 1983. Increase yield and suppression of shoot growth and mite populations of 'd'Anjou' pear trees with nitrogen and paclobutrazol. HortScience, 18: 212-214.

SAS Institute Inc. 1992. SAS/STAT software: changes and enhancements, release 6.07 ed. SAS Institute Inc., Cary, N.C. SAS Tech. Rep. P-229

Sedgley, M., and Griffin, A.R. 1989. Sexual reproduction of tree crops. Academic Press, London.

Smethurst, P.J., Baillie, C., Cherry, M., and Holz, G. 2002. Fertilizer effects on LAI and growth of four Eucalyptus nitens plantations. For. Ecol. Manage. In press.

Swain, T., and Chiappero, C. 1998. Collecting of improved E. nitens seed from ICFR seed orchards. ICFR Newsl. 1998(May): 7-10.

Tibbits, W.N., Boomsma, D.B., and Jarvis, S. 1997. Distribution, biology, genetics, and improvement programs for Eucalyptus globulus and E. nitens around the world. In Proceedings of the 24th Biennial Southern Tree Improvement Conference, 9-12 June 1997. Edited by T. White, D. Huber, and G. Powell. Southern Tree Improvement Committee, Orlando, Fla. pp. 81-95.

Turnbull, C.R.A., Beadle, C.L., McLeod, R., and Cherry, M.L. 1997. Clearing with excavators and nitrogen fertiliser increases the yield of Eucalyptus nitens in plantations established on a native forest site in southern Tasmania. Aust. For. 60: 109-115.

Wang, W.J., Smethurst, P.J., and Holz, G.K. 1998. Nitrogen fluxes in surface soils of 1-2-year-old eucalypt plantations in Tasmania. Aust. J. Soil Res. 36: 17-29.

Wheeler, N.C., Ying, C.C., and Murphy, J.C. 1982. Effect of accelerating growth on flowering in lodgepole pine seedlings and grafts. Can. J. For. Res. 12: 533-537.

Williams, D.R., Ross, J.J., Reid, J.B., and Potts, B.M. 1999. Response of Eucalyptus nitens seedlings to gibberellin biosynthesis inhibitors. Plant Growth Regul. 27: 125-129. 